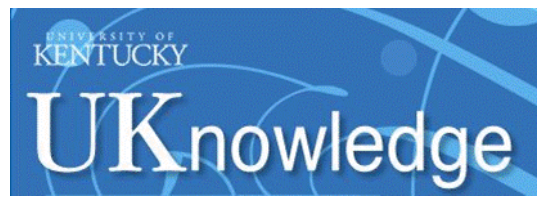

University of Kentucky

UKnowledge

Preventive Medicine and Environmental Health

Presentations

Preventive Medicine and Environmental Health

January 2007

\title{
Public Health Performance
}

F. Douglas Scutchfield MD

University of Kentucky, scutch@uky.edu

Follow this and additional works at: https://uknowledge.uky.edu/pmeh_present

Part of the Education Commons, Life Sciences Commons, Medicine and Health Sciences Commons, and the Social and Behavioral Sciences Commons

Right click to open a feedback form in a new tab to let us know how this document benefits you.

\section{Repository Citation}

Scutchfield, F. Douglas MD, "Public Health Performance" (2007). Preventive Medicine and Environmental Health Presentations. 10.

https://uknowledge.uky.edu/pmeh_present/10

This Presentation is brought to you for free and open access by the Preventive Medicine and Environmental Health at UKnowledge. It has been accepted for inclusion in Preventive Medicine and Environmental Health Presentations by an authorized administrator of UKnowledge. For more information, please contact UKnowledge@lsv.uky.edu. 


\section{Public Health Performance}

F. Douglas Scutchfield, MD

Bosomworth Professor, University of Kentucky

And

Michelyn Bhandari, DrPH, MPH

Assistant Professor, Eastern Kentucky University 


\section{History of Public Health \\ Performance Measurement}

- 1914 AMA State Health Department Performance

- 1925 APHA LPHD Appraisal

- 1945 Emerson's Basic Six

- 1988 The Institute of Medicine's Report, The Future of Public Health

- Early 1990s Miller and Turnock 20, APEX/PH, 10 EPHS

- 1997 National Public Health Performance Standards Program 


\section{Essential PH Services}

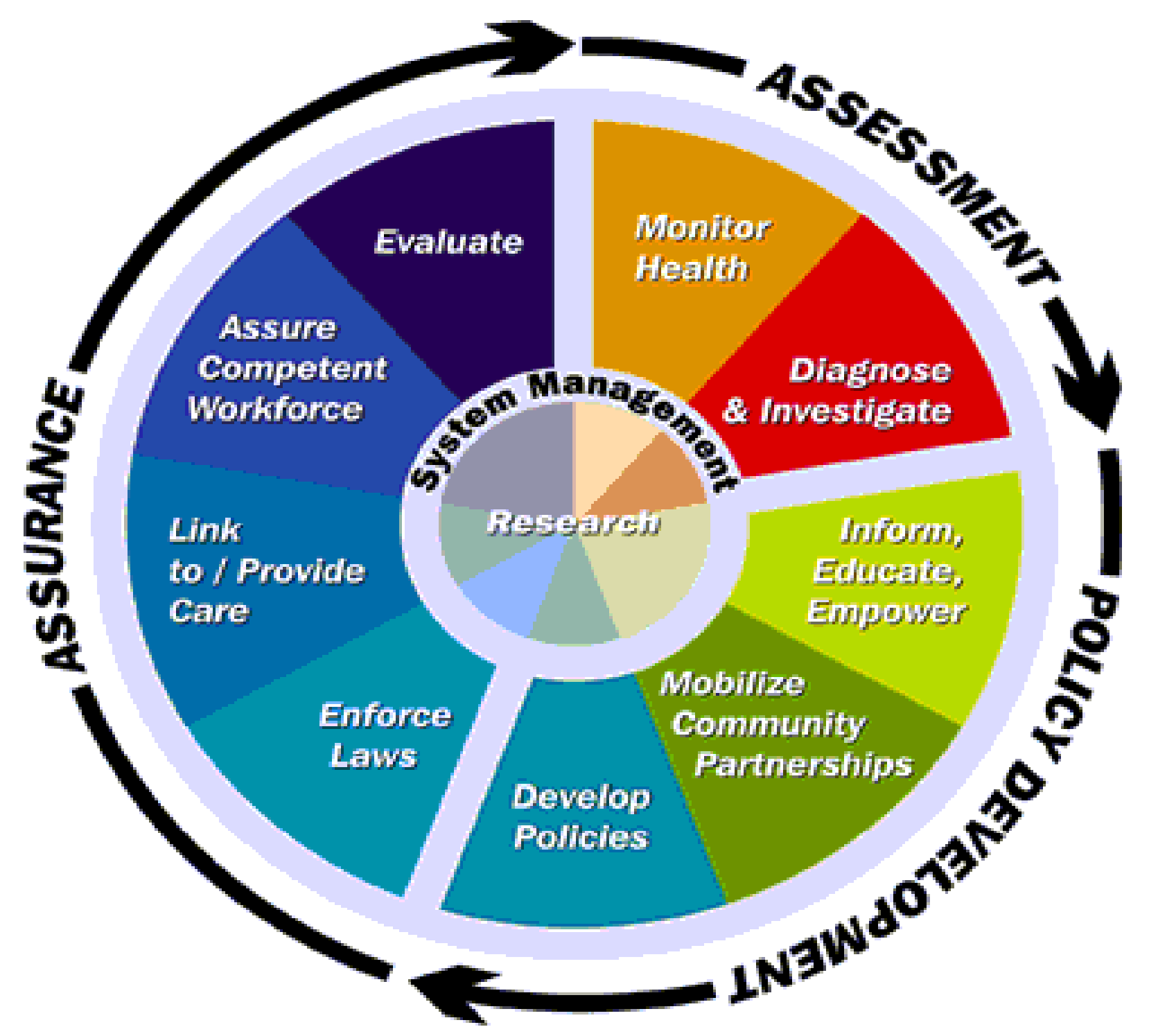




\section{Miller Turnock 20}

Assessment

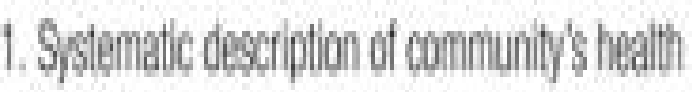
status and heath nead?

2. Populatin-based surve of hea th behavion?

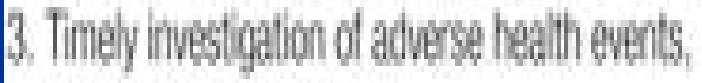
dutbogks, and hadod?

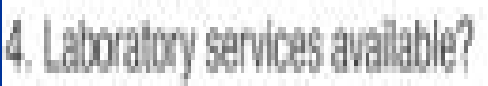

5. Analysis of vioity halth neads, health resource, and populatong at rish?

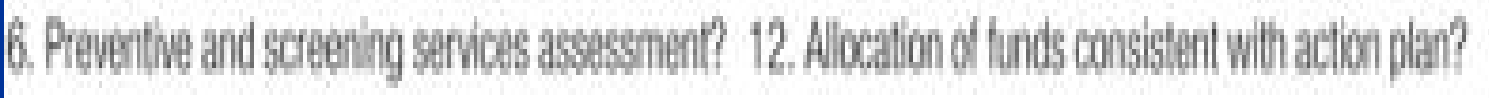

Policy making

7. Suppont and comminuticatan notwork of

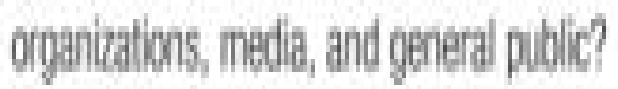

8. Intorm elected officials about pubich health Inpact of ther dilbertors?

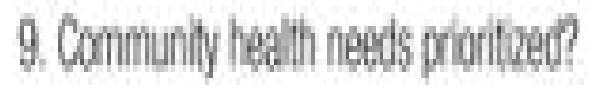

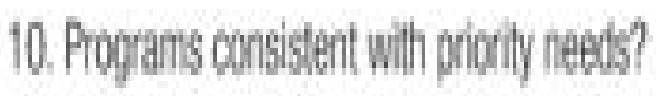

11. Acton plain developer?

\section{Assurance}

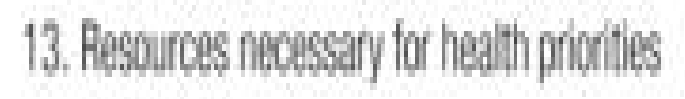
deplogel?

14. LPAA self-rastesment?

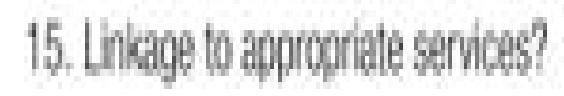

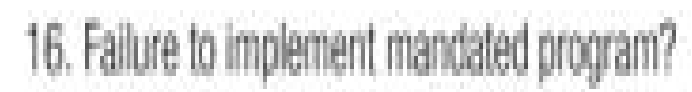

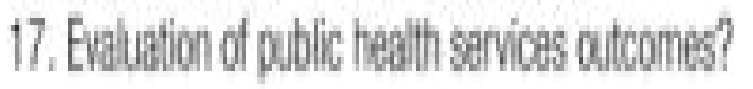

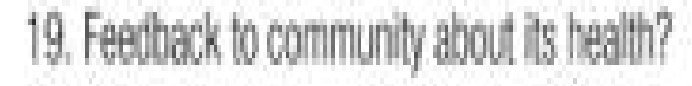

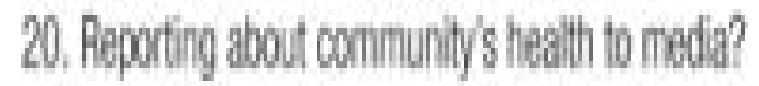




\section{NPHPSP}

\section{Assessment Instruments}

- State public health system

- Local public health system

- Local governance

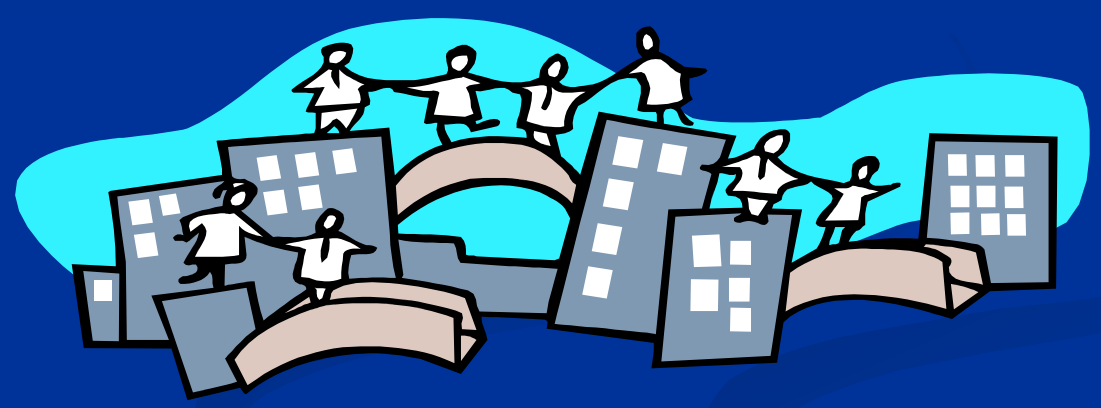

Partners

$\square \mathrm{CDC}$

- APHA

- ASTHO

- NACCHO

- NALBOH

$\square$ NNPHI

$\square \mathrm{PHF}$ 


\section{NPHPSP Mission and Goals}

To improve the quality of public health practice and performance of public health systems by:

1. Providing performance standards for public health systems and encouraging their widespread use;

2. Engaging and leveraging national, state, and local partnerships to build a stronger foundation for public health preparedness;

3. Promoting continuous quality improvement of public health systems; and

4. Strengthening the science base for public health practice improvement. 


\section{Essential Service \# 2: Diagnose and Investigate Health Problems and Health Hazards in the Community}

\section{This service includes:}

- Epidemiological investigations of disease outbreaks and patterns of infectious and chronic diseases and injuries, environmental hazards, and other health threats.

- Active infectious disease epidemiology programs.

- Access to a public health laboratory capable of conducting rapid screening and high volume testing.

\section{LPHS Model Standard 2.1: Identification and Surveillance of Health Threats}

Surveillance systems are designed and maintained to monitor health events, to identify changes or patterns, and to investigate underlying causes or factors. Epidemiological and behavioral science techniques are used to collect data to identify risk factors for health threats. Local public health surveillance systems are integrated with national and state surveillance systems to provide comprehensive monitoring of health events using consistent collection and reporting procedures. Surveillance data are used to assess and analyze health problems and hazards. Surveillance data are also used to examine the impact of health hazards, behaviors, and risk factors on disease and mortality. Surveillance efforts also alert the LPHS to community and health indicators that may signal public health emergencies (e.g., biological or chemical incidents).

In order to accomplish this, the LPHS:

- Collects timely reportable disease information from community health professionals who submit information on possible disease outbreaks.

- Uses state-of-the-art information technology and communication systems to support surveillance and investigation activities.

- Has access to Masters and/or Doctoral level statistical and epidemiological expertise to assess, investigate, and analyze health threats and health hazards.

- Has a procedure to alert communities to possible health threats and disease outbreaks. 


\section{NPHPSP and MAPP}

NPHPSP is a tool for community health assessment and improvement within MAPP

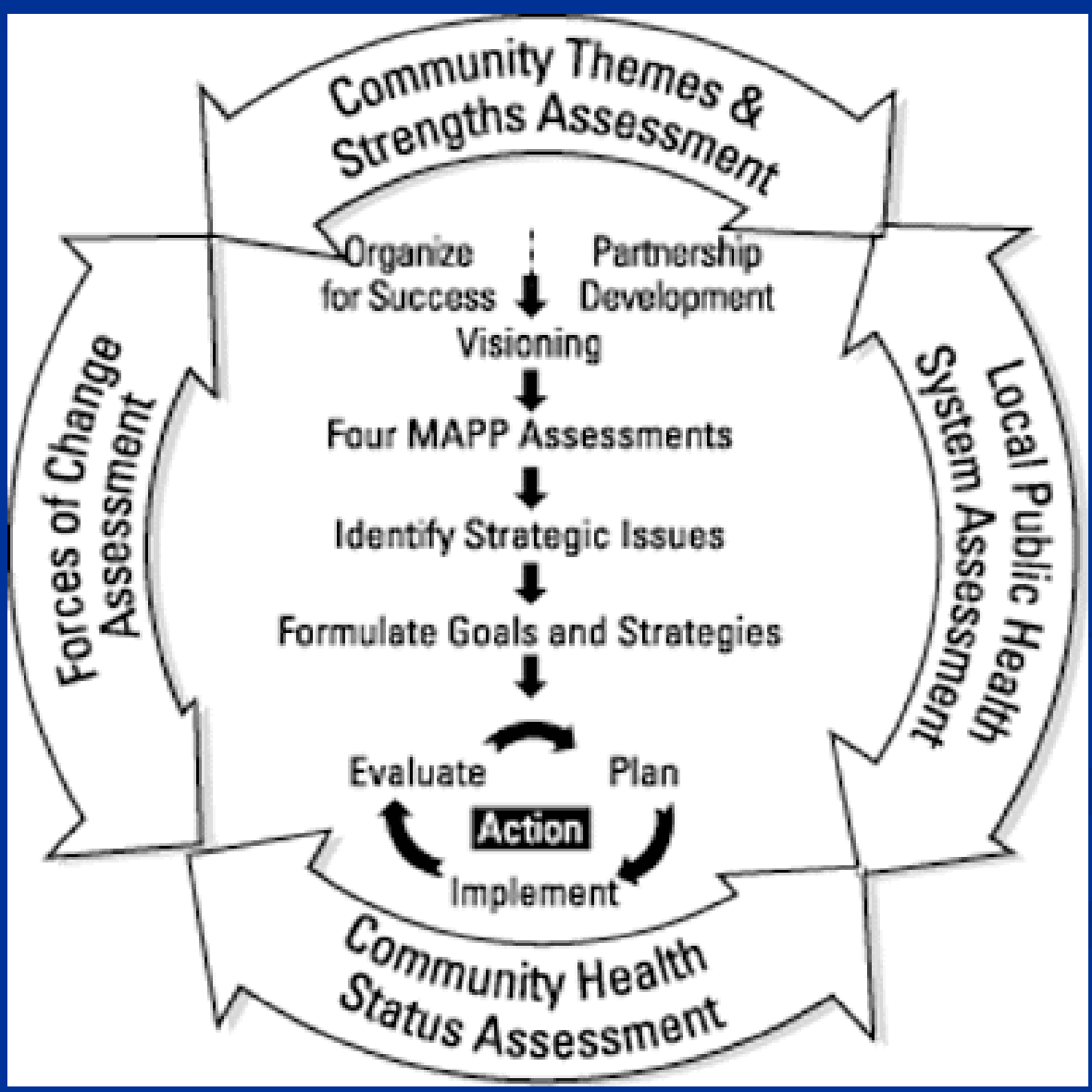




\section{MACRO-CONTEXT}

Social, political, economic forces operating in the overall society (e.g. national economy)

Extent of demand and need for PH services within the population

Social Values and preferences for products of PH system (e.g. clean water)

External forces such as medical delivery system, technological advances, natures of federal, state and local relationships

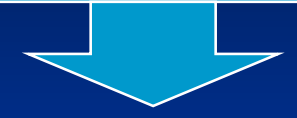

\section{LOCAL PUBLIC HEALTH SYSTEM}

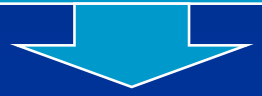

\section{PHS MISSION AND PURPOSE}

Goals and how they are implemented

Performance of the core functions of assessment, policy development, and assurance

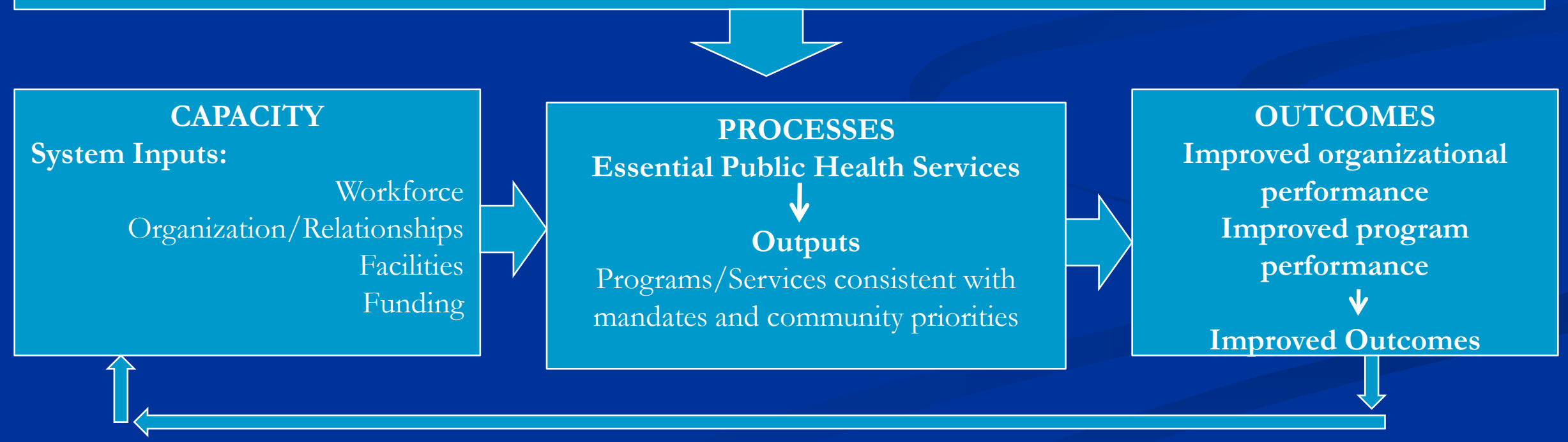

Adapted with permission from Handler, A., Issel, M., and Turnock, B., AJPH, 2001, 91(8): 1235-1239 


\section{Some Illustrative Preliminary}

Work

- Community Size

- Local health department expenditures

- Local funds vs. federal funds

- Total dollars and per capita spending

- Type of jurisdiction

- Governance

- Leadership characteristics

- Partnerships

- Outcomes 


\section{Future Directions For Research}

\section{Data Availability and Use}

- Movement from version 1.0 to 2.0 of the NPHPSP

- Validity and Reliability

- Shortened by nearly $1 / 3$ and simplified vocabulary

- Response category - added distinction between no and 0-25\%

- System Vs. Department

- The Local Governance Instrument

- Only version 2 instrument approved by OMB

- The role of the accreditation standards in examining performance, link to NPHPSP

- Agreement on Performance Standards instruments; common rubrics, HEDIS-like measures and metrics 


\section{Data Availability and Use ( Continued)}

- State health department data: ASTHO survey

- Lack of financial data for either state or local health departments

- Contemporaneous data collection

- Longitudinal data collection

- Lack of common definitions, questions, timing of data collection, need for data harmonization

- What are the right questions? Does it allow for researchers and practitioners to address needed answers; practice research dialogues 


\section{Areas from the Logic Model}

\section{Requiring Answers}

- Environmental impact on performance, Socio Ecologic determinants on model components

- Inputs and their influence on performance; money, people, technology and facilities

- Processes and how they are influenced by inputs and how they influence outcomes; Governance, administration and organization, partnerships, categorical programs and activities 


\section{THE BIG KAHUNA}

How does all this influence outcomes? 


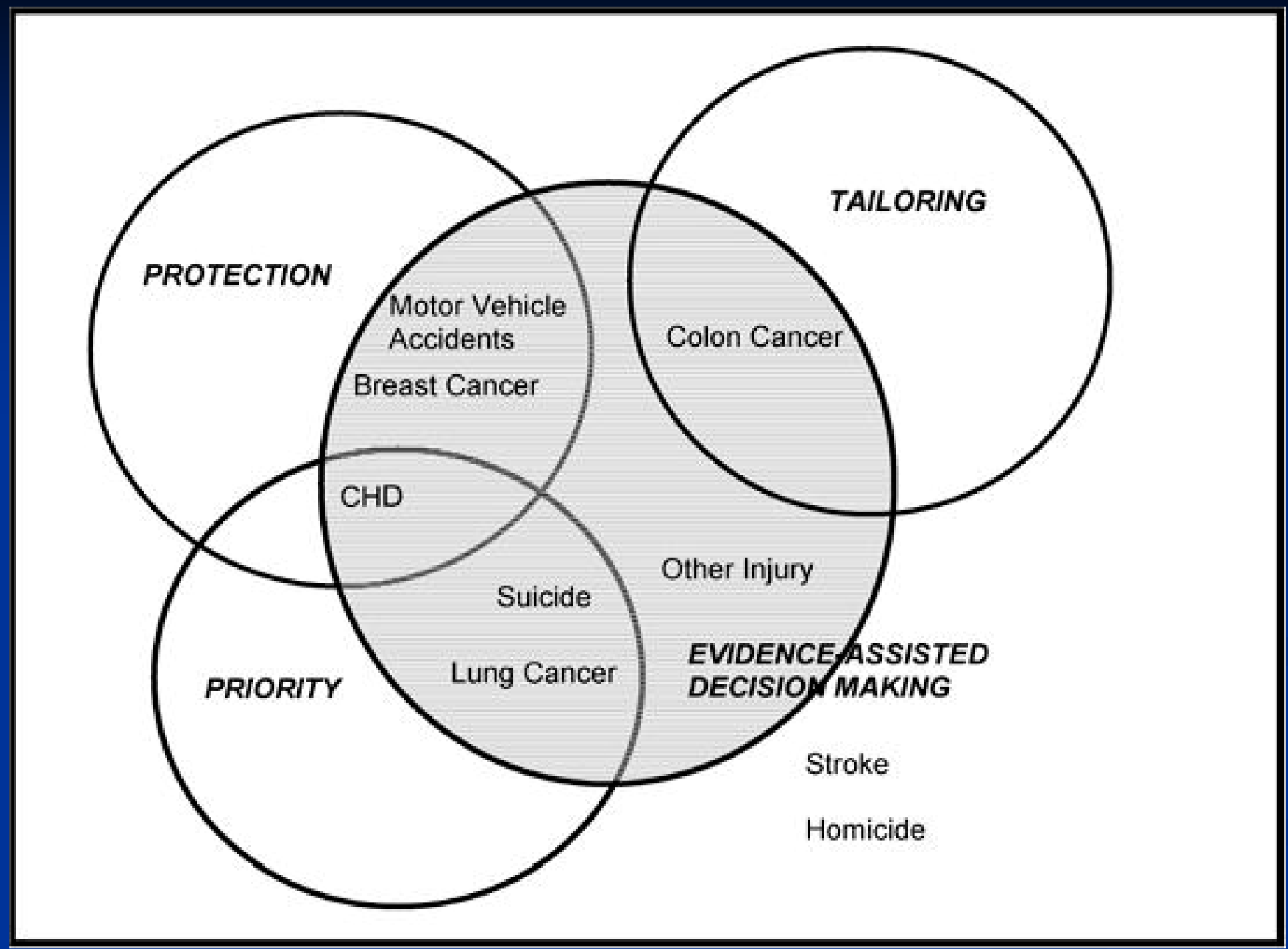

Local Public Health Agency Performance and Community Health Status Kanarek, Norma PhD, MPH; Stanley, Jennifer MA; Bialek, Ron MPP, 2006, Journal of Public Health Practice and Management 12(6) 522-527 


\section{A Desirable State}

We should be able to develop a series of attributes to define a high performing public health system. With that we should be able to identify a series of measures that one would use in identifying areas where we need improvement and a set of standards. Do we eventually come to the place where we can submit a report? Aiming Higher: Results from a State Scorecard on Public Health System Performance: A report of the Commonwealth Fund Commission on a High Performing Health System. 


\section{State Scorecard Summary of Health System Performance Across Dimensions}

State Rank

$\square$ Top Quartile

$\square$ Second Quartile

$\square$ Third Quartile

Bottom Quartile

RANK
1
2
3
3
5
6
7
8
9
10
11
12
13
14
15
16
17
17
19
20
21
22
22
24
24
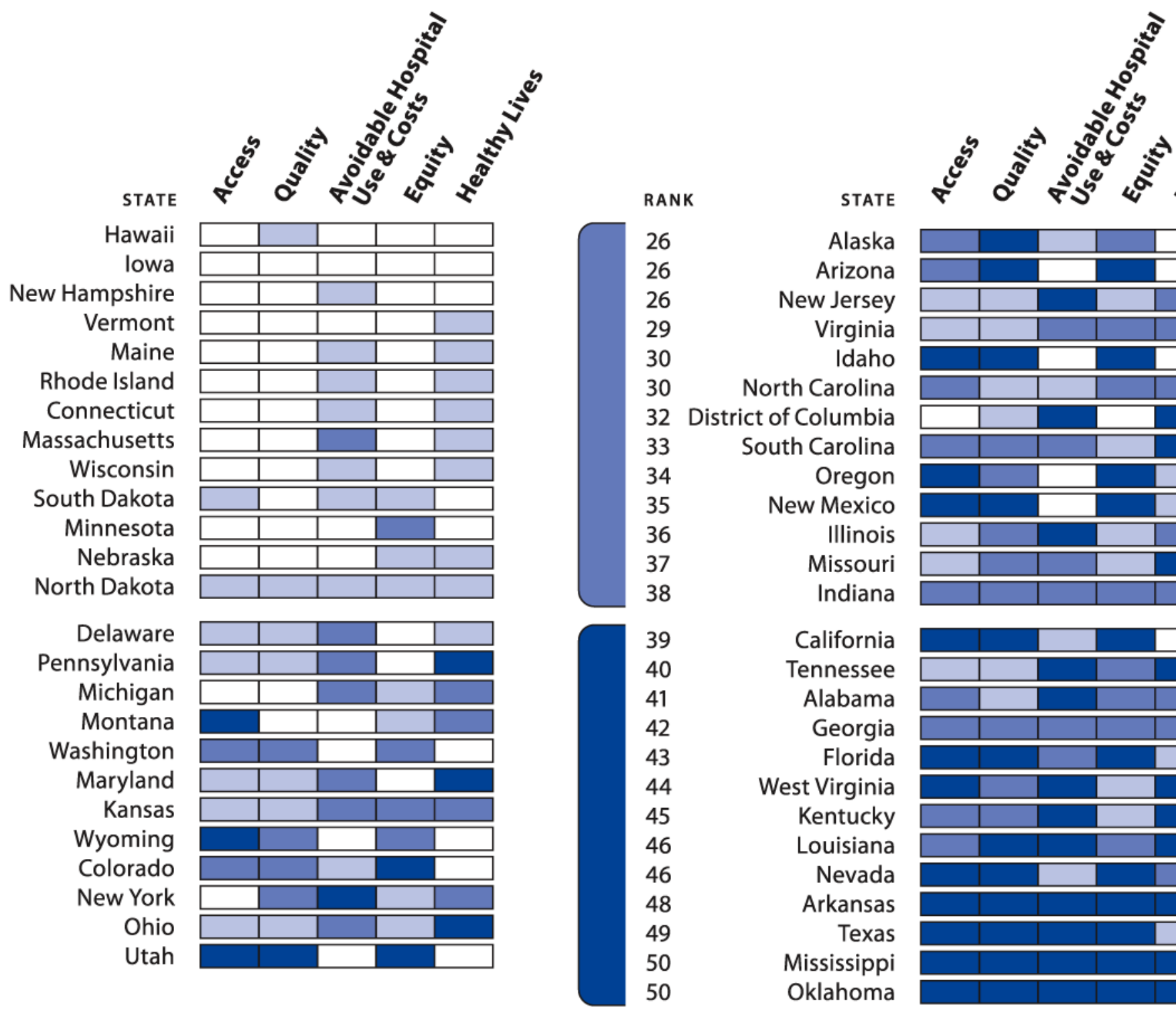

STATE

Alaska

Arizona

New Jersey

Virginia

Idaho

North Carolina

District of Columbia

South Carolina

Oregon

New Mexico

Illinois

Missouri

Indiana

California

Tennessee

Alabama

Georgia

Florida

West Virginia

Kentucky

Louisiana

Nevada

Arkansas

Texas

Mississippi

Oklahoma
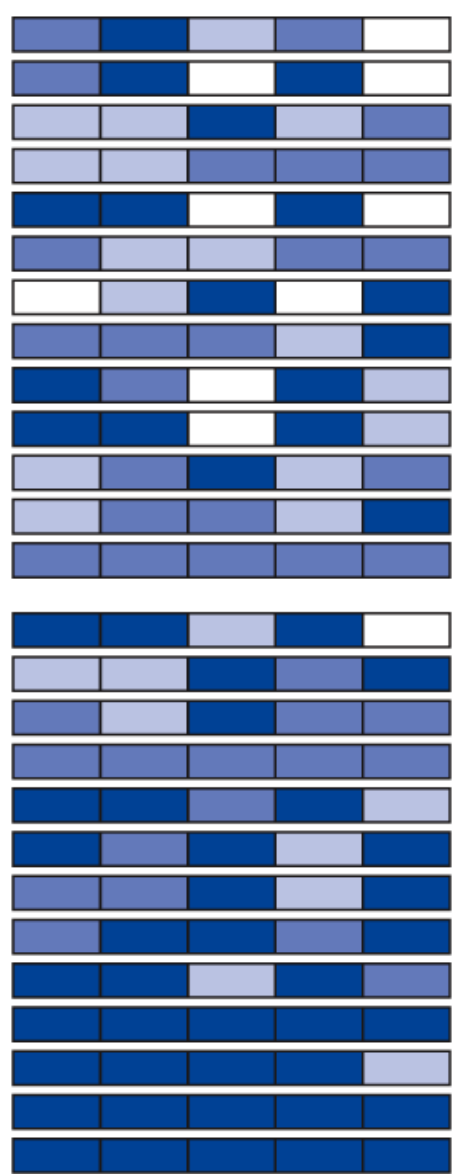


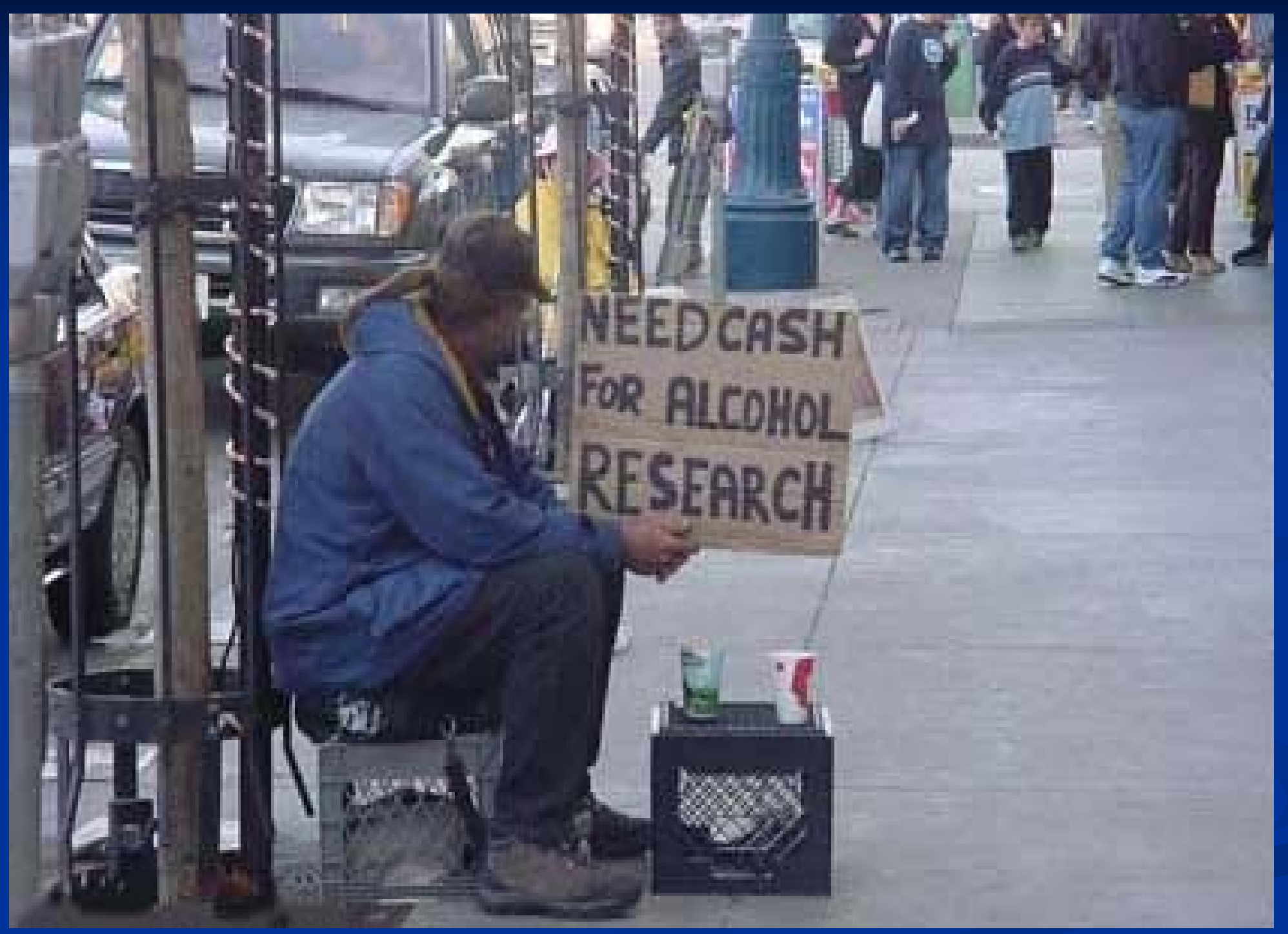




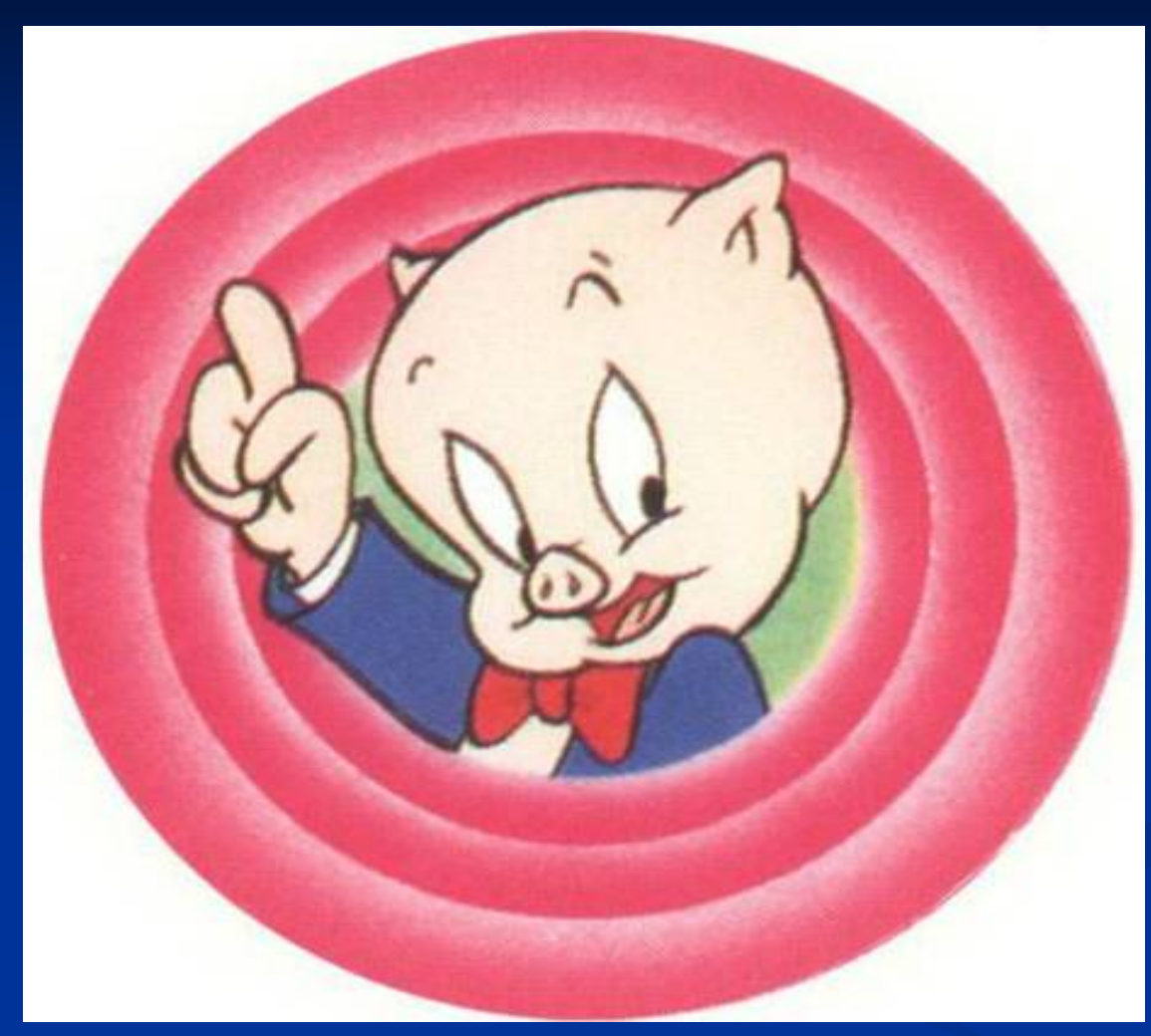

That's adl Golks 